\title{
Correction to: Global surgery and the World Health Organization: indispensable partners to achieve triple billion goals
}

\author{
Ché L. Reddy, MBChB, MPH - Rolvix H. Patterson, BA · Luke Caddell, MS • \\ Adrian W. Gelb, MBChB, FRCPC • Desmond T. Jumbam, MSGH • \\ Lauri Romanzi, MD, MScPH • Isaac Wasserman, MPH • \\ John G. Meara, MD, DMD, MBA
}

Published online: 14 August 2019

(C) Canadian Anesthesiologists' Society 2019

\section{Correction to: Can J Anesth/J Can Anesth https://doi.org/10.1007/s12630-019-01426-4}

The legend of the Figure currently reads: "A formula for advancing surgical system strengthening and World Health Assembly resolution 68.15 through the World Health Organization's thirteenth General Programme of Work (GPW-13). This graphic depicts the three strategic shifts outlined in GPW-13 and ties them to specific avenues for surgical system strengthening to achieve overarching goals. GPW-13 = Thirteenth General Programme of Work;

Ché L. Reddy and Rolvix H. Patterson are co-first authors.

John G. Meara is senior author.

The original article can be found online at https://doi.org/10.1007/ s12630-019-01426-4.

C. L. Reddy, MBChB, MPH (ه) • D. T. Jumbam, MSGH •

J. G. Meara, MD, DMD, MBA

Program in Global Surgery and Social Change, Department of Global Health and Social Medicine, Harvard Medical School,

Boston, Massachusetts, USA

e-mail: chelen_reddy@hms.harvard.edu

Department of Plastic and Oral Surgery, Boston Children's Hospital, Boston, Massachusetts, USA

R. H. Patterson, BA

Program in Global Surgery and Social Change, Department of Global Health and Social Medicine, Harvard Medical School, Boston, Massachusetts, USA
NSOAPs = National Surgical, Obstetric, and Anesthesia Plans; PHC $=$ primary healthcare; SDG $3=$ Sustainable Development Goal 3; UHC = universal health coverage; WHA 68.18 = World Health Assembly resolution 68.15."

The corrected Figure legend should read: A formula for advancing surgical system strengthening and World Health Assembly resolution 68.15 through the World Health Organization's thirteenth General Programme of Work (GPW-13). This graphic depicts the three strategic shifts outlined in GPW-13 and ties them to specific avenues for surgical system strengthening to achieve overarching goals. GPW-13 = Thirteenth General Programme of Work;

Tufts University School of Medicine, Boston, Massachusetts, USA

L. Caddell, MS

Program in Global Surgery and Social Change, Department of Global Health and Social Medicine, Harvard Medical School, Boston, Massachusetts, USA

Miller School of Medicine, University of Miami, Miami, Florida, USA 
NSOAPs = National Surgical, Obstetric, and Anesthesia Plans; PHC $=$ primary healthcare SDG $3=$ Sustainable Development Goal 3; UHC = universal health coverage; WHA 68.15 $=$ World Health Assembly resolution 68.15.
Please note that the actual figure itself was correct.

Publisher's Note Springer Nature remains neutral with regard to jurisdictional claims in published maps and institutional affiliations.

\footnotetext{
A. W. Gelb, MBChB, FRCPC

Department of Anesthesia \& Perioperative Care, University of California San Francisco, San Francisco, California, USA

World Federation of Societies of Anaesthesiologists, London, UK
}

L. Romanzi, MD, MScPH

New York City, New York, USA

I. Wasserman, MPH

Program in Global Surgery and Social Change, Department of Global Health and Social Medicine, Harvard Medical School, Boston, Massachusetts, USA 